Arq. Bras. Med. Vet. Zootec., v.70, n.1, p.287-296, 2018

\title{
Variáveis morfogênicas e estruturais de sorgo forrageiro implantado com diferentes arranjos populacionais sob pastoreio contínuo
}

\author{
[Morphogenetic and structural variables of sorghum implanted with different population \\ arrangements under continuous grazing] \\ L.S. Rodrigues, D.C. Alves Filho, I.L. Brondani, V.S. Silva, P.C. Paula, S.M. Adams, \\ P.M. Martini, A.P.M. Martini
}

Universidade Federal de Santa Maria - Santa Maria, RS

\begin{abstract}
RESUMO
O objetivo do estudo foi avaliar os efeitos da utilização de diferentes arranjos populacionais na implantação de sorgo forrageiro nas características morfogênicas e estruturais do pasto. Os tratamentos foram 22 ou $44 \mathrm{~cm}$ entrelinhas e 12 ou $24 \mathrm{~kg}$ de sementes ha ${ }^{-1}$. O método de pastoreio foi contínuo. Foram utilizadas 36 novilhas, com idade e peso corporal médios de 15 meses de $262 \mathrm{~kg}$. As variáveis morfogênicas não foram influenciadas significativamente $(\mathrm{P}>0,05)$ pelos arranjos populacionais e pelos períodos de avaliação, sendo obtidos taxa de alongamento e senescência foliar de 1,43 e $1,11 \mathrm{~cm} \mathrm{dia}^{-}$ ${ }^{1}$ afilho $^{-1}$, respectivamente, taxa de aparecimento foliar e intervalo de surgimento de folhas de 0,28 folhas dia $^{-1}$ afilho $^{-1}$ e 3,81 dias, filocrono e duração de vida foliar de 72,99 e 351,68 graus dia, nessa ordem. As características estruturais do pasto foram influenciadas pelos períodos de avaliação. Do primeiro para o terceiro período de avaliação, foi verificada uma redução de $65,53 \%$ no número de folhas em alongamento e de $47,79 \%$ no número de folhas vivas.
\end{abstract}

Palavras-chave: espaçamento entrelinhas, densidade de sementes, Sorghum bicolor, taxa de alongamento, taxa de senescência

\begin{abstract}
The objective of the study was to evaluate the effects of using different population arrangements in the implementation of sorghum in the morphogenetic and structural characteristics of the pasture. The treatments were 22 or $44 \mathrm{~cm}$ between rows and 12 or $24 \mathrm{~kg} \mathrm{ha}^{-1}$ of seed. The grazing method was continuous. The sample consisted of 36 heifers with an average age of 15 months and average body weight of $262 \mathrm{~kg}$. Morphogenic variables were not significantly influenced $(P>0.05)$ by population arrangements and evaluation periods, elongation rate and leaf senescence of 1.43 and $1.11 \mathrm{~cm}^{\text {afilho }}{ }^{-1}$ day ${ }^{-1}$ being obtained, respectively, and leaf appearance rate of leaf appearance leaves the range of 0.28 day ${ }^{-1}$ and lafilho 3.81 days, phyllochron and leaf duration of life of 72.99 and 351.68 degree day, in that order. The structural characteristics of the pasture were influenced by evaluation periods. From the first to the third evaluation period, a reduction of $65.53 \%$ in the number of leaves in stretching and $47.79 \%$ in the number of living leaves was verified.
\end{abstract}

Keywords: elongation rate, seed density, Sorghum bicolor, row spacing, senescence rate

\section{INTRODUÇÃO}

A produção de bovinos de corte no Brasil é basicamente realizada em pastagem, e a intensificação produtiva bem como a melhoria dos índices zootécnicos estão associadas à utilização de pastagens cultivadas de inverno e/ou verão. O sorgo forrageiro (Sorghum bicolor) apresenta elevado potencial de utilização devido a características que conferem maior tolerância a períodos de déficit hídrico (Neumann et al., 2005).

Recebido em 6 de junho de 2016

Aceito em 12 de abril de 2017

E-mail: rodrigues_leonel@hotmail.com 
O principal objetivo do manejo da pastagem é conciliar as exigências do animal e a necessidade de manter o potencial produtivo das plantas pastejadas (Hodgson, 1990). É nesse sentido que a manipulação da população de plantas e sua distribuição nas linhas de plantio buscam a obtenção de um ótimo arranjo populacional, a fim de maximizar a exploração de fatores ambientais, como radiação solar, água e nutrientes do solo. Para Coelho et al. (2002), em condições de espaçamento reduzido entre linhas e maiores densidades populacionais, ocorre o aumento da produtividade da cultura pelo melhor aproveitamento dos fatores ambientais.

No entanto, existem recomendações variadas quanto ao espaçamento entrelinhas e à densidade populacional do sorgo forrageiro. Gontijo Neto et al. (2006) recomendam densidade de semeadura de 400 a 600 mil plantas ha $^{-1}$ e espaçamento entrelinhas de 17 a $30 \mathrm{~cm}$; Chielle et al. (2001), espaçamento de $70 \mathrm{~cm}$, com densidade de semeadura de 150 a 250 mil plantas ha $^{-1}$; e Carneiro et al. (2004) indicam espaçamento entrelinhas de $30 \mathrm{~cm}$ e densidade de semeadura superior a 500 mil plantas ha ${ }^{-1}$.

O sucesso na utilização de forragem depende da compreensão dos mecanismos morfofisiológicos e de sua interação com o ambiente. A morfogênese de plantas é descrita com base na taxa de aparecimento e de alongamento de folhas e tempo de vida da folha (Lemaire e Chapman, 1996), que irão determinar as principais características estruturais do pasto. Ainda são escassos na literatura científica estudos que relatem as características morfogênicas e estruturais de sorgo forrageiro.

O objetivo deste estudo é identificar possíveis mudanças nas características morfológicas e estruturais de sorgo forrageiro submetido ao pastoreio contínuo, em função de diferentes espaçamentos entrelinhas e densidade de sementes.

\section{MATERIAL E MÉTODOS}

O experimento foi realizado na Universidade Federal de Santa Maria, localizada na depressão central do Rio Grande do Sul, no período de 15 de novembro de 2013 a 11 de abril de 2014. O clima da região é do tipo Cfa (subtropical úmido), conforme classificação de Köppen
(Alvares et al., 2013). O solo da área experimental pertence à unidade de mapeamento São Pedro e é classificado como Argissolo Vermelho distrófico arênico (Streck et al., 2008). A análise de solo apresentou os seguintes resultados: $\mathrm{pH}$ em $\mathrm{H} 2 \mathrm{O}=4,67 ; \mathrm{P}=13,20 \mathrm{mg} \mathrm{dm}^{3}$; $\mathrm{K}=81,33 \mathrm{mg} \quad \mathrm{dm}^{3} ; \quad \mathrm{Ca}^{+2}=6,17 \mathrm{cmol} \quad \mathrm{dm}^{3}$; $\mathrm{Mg}^{+2}=2,87 \mathrm{cmol} \quad \mathrm{dm}^{3} ; \quad \mathrm{Al}(\%)=16,27$; $\mathrm{V}(\%)=48,73 ;$ CTC ${ }_{\mathrm{pH} 7}=19,00 \mathrm{cmol} \mathrm{dm}^{3} ; \mathrm{MO}$ $(\%)=2,33$.

A área experimental correspondeu a 8,0ha, divididos em oito piquetes com área variável, onde foram manejados os animais testes. A implantação da pastagem ocorreu no dia 15/11/2013, com a utilização de semeadoura em linha em sistema de plantio direto sob resteva de pastagem de aveia (Avena strigosa) e azevém (Lolium multiflorum). Foi realizada dessecação pré-plantio com a aplicação do herbicida glifosato na dosagem de 3,0 litros ha ${ }^{-1}(1080 \mathrm{~g}$ i.a $\left.\mathrm{ha}^{-1}\right)$. Foram aplicados na base $150 \mathrm{~kg} \mathrm{ha}^{-1} \mathrm{de}$ adubo N-P-K com formulação 5-20-20. A quantidade de nitrogênio aplicada em cobertura foi de $45 \mathrm{~kg} \mathrm{ha}^{-1}$ na forma de ureia, divididos em duas aplicações. A semeadoura foi regulada de acordo com as densidades e os espaçamentos utilizados em cada tratamento, a profundidade de semeadura foi de cinco a sete centímetros e o solo apresentava umidade adequada à germinação das sementes.

Os tratamentos propostos foram à combinação de dois espaçamentos, 44 ou $22 \mathrm{~cm}$ entrelinhas, e duas densidades de sementes, 12 ou $24 \mathrm{~kg} \mathrm{ha}^{-1}$, totalizando quatro tratamentos e resultando nas seguintes densidades: 66,$36 ; 56,29 ; 40,91 ; 25,91$ plantas $\mathrm{m}^{-2}$ para os tratamentos E22D24, E44D24, E22D12 e E44D12, respectivamente. Cada tratamento foi composto por duas repetições de área.

O método de pastoreio utilizado foi contínuo, com taxa de lotação variável, conforme metodologia proposta por Moot e Lucas (1952). A massa de forragem foi controlada com o objetivo de manter uma oferta de forragem de $9 \%$ (9kg de MS $100 \mathrm{~kg}$ de $\mathrm{PV}^{-1}$ ), considerando-se a massa de lâminas foliares de sorgo e a massa de forragem das espécies invasoras. Foram utilizadas 36 novilhas de corte oriundas do cruzamento entre as raças Charolês e Nelore, com idade média inicial de 15 meses e $262 \mathrm{~kg}$ de peso vivo inicial, permanecendo em cada piquete 
três novilhas-teste e número variável de reguladores. $\mathrm{O}$ período experimental iniciou em 21 de dezembro de 2013. O período experimental totalizou 63 dias, sendo subdividido em períodos de 21 dias.

Os animais receberam suplementação diária na quantidade de $1 \%$ do peso vivo, sendo regulada semanalmente conforme evolução do peso vivo obtido. Os níveis de proteína bruta e de nutrientes digestíveis totais do suplemento foram de 14,4 e $76,7 \%$, respectivamente, baseados nas exigências nutricionais dos animais. Todos os tratamentos receberam o mesmo suplemento, que foi formulado pela relação de $62,9 \%$ de grão de aveia branca, $35 \%$ de grão de milho, $1 \%$ de ureia e $1,1 \%$ de calcário calcítico.

Na Tab. 1, são apresentadas as médias das variáveis oferta de lâminas foliares, oferta de forragem total, massa de lâminas foliares, massa de forragem total, composição estrutural e relação folha/colmo da pastagem.

Tabela 1. Oferta de lâminas foliares (OLF), oferta de forragem total (OF), massa de lâminas foliares (MLF), massa de forragem total (MF) de sorgo forrageiro implantado sob diferentes arranjos populacionais

\begin{tabular}{|c|c|c|c|c|}
\hline \multirow{2}{*}{$\frac{\text { Espaçamento }(\mathrm{cm})}{\text { Densidade }\left(\mathrm{kg} \mathrm{ha}^{-1}\right)}$} & \multicolumn{2}{|c|}{44} & \multicolumn{2}{|c|}{22} \\
\hline & 12 & 24 & 12 & 24 \\
\hline OLF (kg de MS 100kg de $\mathrm{PV}^{-1}$ ) & 3,49 & 3,52 & 4,57 & 3,31 \\
\hline OF (kg de MS 100kg de $\mathrm{PV}^{-1}$ ) & 8,94 & 8,66 & 13,54 & 8,35 \\
\hline $\operatorname{MLF}\left(\mathrm{kg} \mathrm{MS}^{-1} \mathrm{ha}^{-1}\right)$ & 231,87 & 227,26 & 198,51 & 274,34 \\
\hline $\operatorname{MF}\left(\mathrm{kg} \mathrm{MS}^{-1} \mathrm{ha}^{-1}\right)$ & 1319,35 & 1062,38 & 1559,96 & 1174,75 \\
\hline
\end{tabular}

As avaliações das características morfogênicas do pasto foram realizadas em dois piquetes por tratamento durante os períodos experimentais, por meio da técnica de "perfilhos marcados" (Carrère et al., 1997). As avaliações foram realizadas em intervalos consecutivos de sete dias, e, após quatro medições, novos afilhos foram marcados e avaliados, mantendo-se os mesmos intervalos. As medições foram realizadas no mesmo dia, dentro dos períodos, em todos os piquetes avaliados. Para avaliações, foram marcados com fios telefônicos coloridos 50 afilhos por piquete, divididos em três transectas. A primeira folha de cada afilho foi marcada com corretor ortográfico líquido, para posterior identificação da ocorrência de morte das folhas.

As medidas realizadas consistiram em medir o comprimento da porção verde de cada folha a partir do ponto de intersecção da lâmina foliar com o colmo até o final da lâmina foliar. As folhas em elongação foram medidas a partir da lígula da última folha adulta. Foram consideradas folhas em senescência as que apresentavam mais de $50 \%$ da área de lâmina foliar morta, sendo somente a porção verde medida. Foram identificados o número total de folhas e a condição apresentada por elas em: adulta, alongando, senescente, morta e pastejada. Foram tomadas as medidas da altura de dossel medida no dobramento médio das folhas do afilho; o comprimento do pseudocolmo foi medido a partir do solo até a lígula da última folha totalmente expandida, e o diâmetro do colmo medido na base do afilho.

As variáveis determinadas foram taxa de alongamento foliar, taxa de senescência foliar, taxa de aparecimento foliar, número médio de folhas por afilho, número médio de folhas em alongamento por afilho, número médio de folhas verdes por afilho, filocrono, duração de vida foliar, comprimento do pseudocolmo, altura do dossel e diâmetro do colmo.

Para os cálculos das taxas de elongação e senescência, utilizou-se o valor médio de elongação e senescência por afilho das folhas que não foram pastejadas no período dividido pelos intervalos em dias de cada avaliação. Para o cálculo da taxa de aparecimento foliar, foi 
utilizado o número de folhas novas surgidas no período dividido pelo intervalo entre as avaliações em dias. O filocrono foi calculado a partir de regressão entre o valor da soma térmica acumulada durante os intervalos de avaliação do período e o número médio de folhas dos afilhos em cada intervalo considerado, sendo o valor de filocrono o valor inverso do coeficiente angular dessa regressão, expresso em graus-dia (GD).

O cálculo da soma térmica diária acumulada baseou-se na equação: $\left(\left(\mathrm{T}^{\circ} \mathrm{Mx}+\mathrm{T}^{\circ} \mathrm{Mn}\right) 2^{-1}\right)$ $10^{\circ} \mathrm{C}$, em que: $\mathrm{T}^{\circ} \mathrm{Mx}=$ temperatura máxima, $\mathrm{T}^{\circ} \mathrm{Mn}=$ temperatura mínima e $10^{\circ} \mathrm{C}$ é a temperatura base de crescimento da planta
(Pedroso et al., 2009). A duração de vida foliar foi obtida por meio do produto do número médio de folhas verdes por afilho pelo valor do filocrono, sendo consideradas folhas verdes aquelas que não estavam em senescência.

A Comissão de Ética no Uso de Animais da Universidade Federal de Santa Maria (UFSM) aprovou o protocolo desta pesquisa, sob o parecer $n^{\circ} 128 / 2014$.

Na Tab. 2, são apresentados os dados referentes à insolação, precipitação, temperaturas máximas e mínimas registradas durante o período experimental e a série histórica.

Tabela 2. Insolação, precipitação pluviométrica e de temperaturas, médias mensais de novembro de 2013 a abril de 2014 e médias históricas (1984 - 2014) para a cidade de Santa Maria-RS

\begin{tabular}{ccccccc}
\hline Série histórica & Nov & Dez & Jan & Fev & Mar & Abr \\
\hline Insolação (horas) & 223,75 & 250,41 & 248,69 & 201,5 & 212,11 & 178,74 \\
Precipitação $(\mathrm{mm})$ & 116,9 & 144,73 & 155,97 & 128,58 & 124,49 & 155,61 \\
Temp. máxima $\left({ }^{\circ} \mathrm{C}\right)$ & 27,85 & 30,39 & 31,02 & 30,11 & 29,06 & 25,58 \\
Temp. mínima $\left({ }^{\circ} \mathrm{C}\right)$ & 17,99 & 18,49 & 17,77 & 19,72 & 14,35 & 12,52 \\
\hline Período experimental - 2014 & Nov & Dez & Jan & Fev & Mar & Abr \\
\hline Insolação (horas) & 229,20 & 286,30 & 229,30 & 218,90 & 212,60 & 186,20 \\
Precipitação $(\mathrm{mm})$ & 294,50 & 92,80 & 132,3 & 109 & 226,9 & 105,1 \\
Temp. máxima $\left({ }^{\circ} \mathrm{C}\right)$ & 28,73 & 32,12 & 32,62 & 32,13 & 28,4 & 25,8 \\
Temp. mínima $\left({ }^{\circ} \mathrm{C}\right)$ & 17,52 & 19,70 & 21,23 & 20,64 & 17,2 & 15,7 \\
\hline
\end{tabular}

Fonte: Instituto Nacional de Meteorologia - Estação Santa Maria RS (Banco..., 2014).

O delineamento experimental utilizado foi o inteiramente ao acaso, com três repetições por área, em esquema fatorial 2 x 2 (dois espaçamentos entrelinhas e duas densidades de sementes). Foi realizado teste de normalidade de Shapiro-Wilk em todas as variáveis, para verificar o comportamento normal dos resíduos. Os dados foram analisados pelo procedimento MIXED (Statistical Analysis System - SAS Studio University Edition, versão 3.5), considerando-se medidas repetidas no tempo as medidas tomadas em cada período experimental, sendo considerada a interação entre espaçamento entrelinhas e a densidade de sementes, e, quando não significativa a interação, os efeitos foram considerados de forma independente. Foi realizada análise de correlação pelo procedimento CORR (Statistical Analysis System - SAS Studio University Edition, versão 3.5). As médias, quando diferentes significativamente, foram comparadas pelo teste de t em nível de $5 \%$ de significância. $\mathrm{O}$ modelo matemático adotado foi representado por:

$$
Y i j k=\mu+E+D+(E x D)+R k(E x D)+P j+(P j \times E x D)+e i j k,
$$

em que: Yijk representa as variáveis dependentes; $\mu$ a média de todas as observações; E o efeito do espaçamento; D o efeito da densidade; (E x D) o efeito da interação entre espaçamento e densidade; Rk (E x D) o efeito da k-ésima repetição dentro de cada tratamento; $\mathrm{Pj}$ o efeito do j-ésimo período; ( $\mathrm{Pj}$ x E x D) o efeito da interação entre período, espaçamento e densidade; eijk o erro total experimental. 


\section{RESULTADOS E DISCUSSÃO}

Os arranjos populacionais ( $\mathrm{E} \quad \mathrm{x} \quad \mathrm{D})$ não influenciaram nas características morfogênicas do sorgo forrageiro (Tab. 3), da mesma forma que o espaçamento entrelinhas (E) e a densidade de sementes (D) quando analisados de forma independente. A taxa de elongação foliar foi similar entre os tratamentos $(\mathrm{P}=0,427)$, com média de $1,43 \mathrm{~cm} \mathrm{dia}{ }^{-1}$ afilho $^{-1}$. Era esperada maior taxa de alongamento para o tratamento com maiores densidades de plantas em razão de um maior sombreamento das folhas situadas em menor nível, que tenderiam a buscar maior luminosidade. Pereira et al. (2011) relatam efeitos maiores na taxa de alongamento foliar para diferentes doses de nitrogênio do que o efeito da densidade de plantas em capimmombaça (Panicum maximum Jacq. cv Mombaça).

Os resultados obtidos em pesquisas demonstram que existe uma ampla variação na taxa de elongação foliar em gramíneas tropicais. Lopes et al. (2017) observaram para Brachiaria decumbens uma taxa de elongação foliar de $1,88 \mathrm{~cm} \mathrm{dia}{ }^{-1}$ afilho $^{-1}$. Rodrigues et al. (2014) registraram, para capim-xaraés, taxa de elongação foliar entre 4,47 e 7,65 $\mathrm{cm} \mathrm{dia}^{-1}$ afilho 1 .

Tabela 3. Médias para taxa de elongação foliar (TAlF), taxa de senescência foliar (TSF), taxa de aparecimento foliar (TApF), intervalo de surgimento de folhas (IntSurg), filocrono e duração da vida foliar (Vida foliar) de sorgo forrageiro implantado sob diferentes arranjos populacionais

\begin{tabular}{|c|c|c|c|c|c|c|c|c|}
\hline \multirow{2}{*}{$\begin{array}{c}\text { Espaçamento (E) } \\
\text { Densidade (D) }\end{array}$} & \multicolumn{2}{|c|}{44} & \multicolumn{2}{|c|}{22} & \multirow{2}{*}{ EP } & \multicolumn{3}{|c|}{$\mathrm{P}$} \\
\hline & 12 & 24 & 12 & 24 & & $\mathrm{E}$ & $\mathrm{D}$ & ExD \\
\hline TAlF $\left(\mathrm{cm} \mathrm{dia}^{-1}\right.$ afilho $\left.^{-1}\right)$ & 1,56 & 1,63 & 1,37 & 1,17 & 0,18 & 0,084 & 0,734 & 0,462 \\
\hline TSF $\left(\mathrm{cm} \mathrm{dia}^{-1} \mathrm{afilho}^{-1}\right)$ & 0,93 & 1,35 & 1,23 & 0,93 & 0,22 & 0,795 & 0,772 & 0,119 \\
\hline TApF (folha dia ${ }^{-1}$ afilho $^{-1}$ ) & 0,28 & 0,29 & 0,25 & 0,32 & 0,03 & 0,914 & 0,262 & 0,361 \\
\hline IntSurg (dias) & 3,79 & 3,75 & 4,23 & 3,45 & 0,43 & 0,876 & 0,305 & 0,376 \\
\hline Filocrono (graus-dia) & 94,37 & 62,72 & 74,35 & 60,50 & 13,76 & 0,429 & 0,114 & 0,525 \\
\hline Vida foliar (graus-dia) & 458,40 & 278,41 & 357,20 & 312,72 & 76,89 & 0,739 & 0,082 & 0,941 \\
\hline
\end{tabular}

$\mathrm{E}=$ espaçamento $(\mathrm{cm}) ; \mathrm{D}=$ densidade $\left(\mathrm{kg} \mathrm{ha}^{-1}\right) ; \mathrm{ExD}=$ interação espaçamento $\mathrm{x}$ densidade; $\mathrm{EP}=$ erro-padrão da média; $\mathrm{P}=$ valor de probabilidade.

No último período de avaliação (15/02 a 11/03), a taxa de elongação foliar foi reduzida quando este foi comparado ao primeiro e ao segundo período, porém sem diferença significativa $(\mathrm{P}=0,101)$, o que está relacionado com o estágio de crescimento da planta coincidir com a diferenciação floral, quando é destinada grande parte de seus fotoassimilados para a inflorescência, diminuindo a elongação foliar.

Os arranjos populacionais não influenciaram a taxa de senescência foliar $(\mathrm{P}=0,119)$, o que pode estar relacionado ao fato de que a duração de vida foliar também não tenha sido influenciada, não ocorrendo maior senescência foliar. Ao longo dos períodos de avaliação, a taxa de senescência não foi diferente significativamente $(\mathrm{P}=0,765)$. Pedroso et al. (2009) observaram taxa de senescência foliar para milheto de $0,90 \mathrm{~cm} \mathrm{dia}^{-}$ 1, valor muito próximo ao encontrado por Martuscello et al. (2005) e Fagundes et al. (2006) ao estudarem gramíneas perenes de verão.

A dinâmica do processo de acúmulo de biomassa pode ser visualizada por meio da relação entre a taxa de alongamento foliar e a taxa de senescência foliar, em que as taxas de alongamento foliar foram 1,$68 ; 1,21 ; 1,11 ; 1,26$ vezes superiores às de senescência para os arranjos populacionais E44D12, E44D24, E22D12 e E22D24, respectivamente. Quando a mesma análise é feita em relação aos períodos de avaliação, fica marcado um rápido decréscimo do crescimento da pastagem, em que se obtêm relações de 1,$52 ; 1,39$ e 0,92 com o avançar dos períodos de avaliação. Ou seja, a partir do dia 
$15 / 02$, a pastagem passou a ter maior taxa de senescência do que de alongamento de folhas, o que refletiu na diminuição na oferta de lâminas foliares no terceiro período de avaliação. Essa estrutura observada no decorrer dos períodos de avaliação, com menor número de folhas verdes e em elongação e maior número de folhas em senescência, indica a condição de envelhecimento do pasto e a provável redução no acúmulo líquido de forragem em relação aos períodos anteriores, pois esse acúmulo decorre do balanço entre o crescimento e a senescência do pasto (Hodgson, 1990).

A taxa de aparecimento foliar não foi influenciada $(\mathrm{P}=0,560)$ pelos arranjos populacionais e pelos períodos de avaliação $(\mathrm{P}=0,153)$, sendo obtido nos tratamentos, em média, 0,29 folha $\mathrm{dia}^{-1}$, o que pode estar relacionado com a similaridade da altura do dossel e o comprimento do pseudocolmo (Tab. 4) obtido nos tratamentos. Segundo Martins et al. (2014), a taxa de aparecimento foliar pode ser influenciada pela altura do dossel devido ao aumento do comprimento da bainha das folhas sucessivas de gramíneas cespitosas, quando o maior comprimento da bainha induz a folha a um maior comprimento para expansão. Martins et al. (2005) encontraram valores para taxa de aparecimento foliar de milheto de 0,103 a 0,202 folhas $\mathrm{dia}^{-1}$. O intervalo de surgimento de folhas médio obtido entre os tratamentos foi de 3,80 dias para o surgimento de uma nova folha. Martins et al. (2005) observaram, em média, 9,13 dias para o aparecimento de uma nova folha em pastagem de milheto manejadas com duas alturas. Segundo Pompeu et al. (2009), a taxa de aparecimento foliar é influenciada por fatores ambientais, tais como temperatura, intensidade luminosa, disponibilidade de água, umidade e nutrientes, principalmente nitrogênio.

Tabela 4. Médias para taxa de elongação foliar (TAlF), taxa de senescência foliar (TSF), taxa de aparecimento foliar (TApF), intervalo de surgimento de folhas (IntSurg), filocrono e duração da vida foliar (Vida foliar) expressos por período de avaliação

\begin{tabular}{|c|c|c|c|c|c|}
\hline & \multicolumn{3}{|c|}{ Período } & \multirow{2}{*}{$\mathrm{EP}$} & \multirow{2}{*}{$\mathrm{P}$} \\
\hline & $21 / 12-04 / 01$ & $11 / 01-01 / 02$ & $15 / 02-11 / 03$ & & \\
\hline TAlF (cm dia ${ }^{-1}$ afilho $^{-1}$ ) & 1,51 & 1,59 & 1,10 & 0,13 & 0,155 \\
\hline TSF (cm dia ${ }^{-1}$ afilho $^{-1}$ ) & 0,99 & 1,14 & 1,19 & 0,20 & 0,765 \\
\hline TApF (folha dia ${ }^{-1}$ afilho $^{-1}$ ) & 0,31 & 0,29 & 0,24 & 0,03 & 0,173 \\
\hline IntSurg. (dias) & 3,34 & 3,61 & 4,47 & 0,74 & 0,153 \\
\hline Filocrono (graus-dia) & 61,44 & 71,41 & 86,10 & 11,38 & 0,353 \\
\hline Vida foliar (graus-dia) & 432,82 & 327,01 & 295,22 & 62,15 & 0,375 \\
\hline
\end{tabular}

$\mathrm{EP}=$ erro-padrão da média; $\mathrm{P}=$ valor de probabilidade.

O filocrono não foi influenciado significativamente pelos arranjos populacionais $(\mathrm{P}=0,338)$ e pelos períodos de avaliação $(\mathrm{P}=0,353)$, sendo obtidos, em média, 72,99 graus-dia, refletindo a similaridade das taxas de aparecimento foliar nos tratamentos. Os valores de filocrono observados por Pedroso et al. (2009) para outra espécie forrageira de estação quente, como o milheto, variaram de 93 a 128 graus-dia.

A duração de vida foliar não foi afetada $(\mathrm{P}=0,941)$ pelos arranjos populacionais testados e ao longo dos períodos de avaliação $(\mathrm{P}=0,360)$, uma vez que ela é dependente do filocrono e do número de folhas vivas (Tab. 5), variáveis essas que, por sua vez, também não foram influenciadas significativamente. A duração de vida foliar média obtida no presente estudo foi de 351,68 graus-dia. Garcez Neto et al. (2002) relatam valores de duração de vida foliar de 311 a 480 graus-dia para Panicum maximum cv. Mombaça. A duração de vida foliar apresenta um papel fundamental no manejo de pastagens, uma vez que é indicador da intensidade e frequência de pastejos para que se tenham índices de áreas foliares próximos aos das máximas taxas de crescimento. 
Variáveis morfogênicas...

Tabela 5. Médias para o número de folhas em alongamento (NFA), número de folhas vivas por afilho (NFV), altura de pseudocolmo (Pseudocolmo) e altura de dossel de sorgo forrageiro implantado sob diferentes arranjos populacionais

\begin{tabular}{|c|c|c|c|c|c|c|c|c|}
\hline \multirow{2}{*}{$\frac{\text { Espaçamento (E) }}{\text { Densidade (D) }}$} & \multicolumn{2}{|c|}{44} & \multicolumn{2}{|c|}{22} & \multirow{2}{*}{ EP } & \multicolumn{3}{|c|}{$\mathrm{P}$} \\
\hline & 12 & 24 & 12 & 24 & & $\mathrm{E}$ & $\mathrm{D}$ & ExD \\
\hline NFA ( $n^{\circ}$ de folhas) & 1,08 & 0,83 & 1,00 & 0,85 & 0,218 & 0,979 & 0,505 & 0,806 \\
\hline $\operatorname{NFV}\left(n^{\circ}\right.$ de folhas) & 4,89 & 5,03 & 4,99 & 5,01 & 0,720 & 0,961 & 0,909 & 0,959 \\
\hline Pseudocolmo $(\mathrm{cm})$ & 40,64 & 40,48 & 37,97 & 37,20 & 4,639 & 0,529 & 0,921 & 0,949 \\
\hline Diâmetro do colmo $(\mathrm{cm})$ & 1,07 & 0,94 & 1,00 & 0,89 & 0,04 & 0,523 & 0,220 & 0,879 \\
\hline Altura dossel $(\mathrm{cm})$ & 59,30 & 60,91 & 58,58 & 53,44 & 7,239 & 0,671 & 0,446 & 0,521 \\
\hline
\end{tabular}

$\mathrm{E}=$ espaçamento $(\mathrm{cm}) ; \mathrm{D}=$ densidade $\left(\mathrm{kg} \mathrm{ha}^{-1}\right) ; \mathrm{ExD}=$ interação espaçamento $\mathrm{x}$ densidade; $\mathrm{EP}=$ erro-padrão da média; $\mathrm{P}=$ valor de probabilidade.

Não houve interação entre os arranjos populacionais e os períodos de avaliação $(\mathrm{P}>0,05)$ para as variáveis número de folhas em alongamento, número de folhas vivas e altura de pseudocolmo. As variáveis foram semelhantes entre os arranjos populacionais testados e diferiram entre os períodos de avaliação.

As características estruturais da pastagem de sorgo forrageiro não foram influenciadas significativamente pelos arranjos populacionais (E x D), pela densidade de sementes (D) e pelo espaçamento entrelinhas (E), o que pode ser atribuído ao fato de que as características morfogênicas e estruturais tenham uma alta correlação, bem como não tenham sido influenciadas pelos arranjos populacionais. Segundo Lemaire e Chapman (1996), as características estruturais de uma planta forrageira são reflexos da combinação das características morfogênicas. Pode se observar (Tab. 6) que as características estruturais foram mais influenciadas com o avançar do ciclo da pastagem, refletido ao longo dos períodos de avaliação.
O número total de folhas não diferiu significativamente $(\mathrm{P}=0,659)$ entre os arranjos populacionais, sendo observados valores médios de 6,09 folhas perfilho ${ }^{-1}$ para ambos os tratamentos. Lopes et al. (2017) e Martins et al. (2005) descrevem valores de 5,10 e 5,53 folhas vivas afilho ${ }^{-1}$ para Brachiaria decumbens e milheto, respectivamente. O número de folhas vivas foi influenciado pelos períodos de avaliação ( $\mathrm{P}=0,0001)$, quando se observa uma redução de $31,71 \%$ do primeiro período (21/12 a 04/01) para o segundo período (11/01 a 01/02) no número de folhas vivas, que passou de 6,78 para 4,63 folhas perfilho ${ }^{-1}$. Do segundo período para o terceiro período (15/02 a 11/03), houve redução de $23,54 \%$, de 4,63 para 3,54 folhas vivas perfilho ${ }^{-1}$, o que pode estar relacionado com o avanço do estágio vegetativo e o decréscimo da temperatura. $\mathrm{O}$ mesmo comportamento ocorreu no número de folhas em alongamento, que foi reduzido do primeiro (21/12 a 04/01) para o terceiro (15/02 a 11/03) período de avaliação em $65,53 \%$, de 2,35 para 0,81 folhas afilho- ${ }^{-1}$.

Tabela 6. Médias para o número de folhas em alongamento (NFA), número de folhas vivas por afilho (NFV), altura de pseudocolmo (Pseudocolmo) e altura de dossel expressos por período de avaliação

\begin{tabular}{|c|c|c|c|c|c|}
\hline & \multicolumn{3}{|c|}{ Período } & \multirow{2}{*}{$\mathrm{EP}$} & \multirow{2}{*}{$\mathrm{P}^{*}$} \\
\hline & 21/12-04/01 & $11 / 01-01 / 02$ & $15 / 02-11 / 03$ & & \\
\hline NFA & $2,35^{\mathrm{a}}$ & $1,13^{b}$ & $0,81^{\mathrm{b}}$ & 0,13 & 0,0001 \\
\hline NFV & $6,78^{\mathrm{a}}$ & $4,63^{\mathrm{b}}$ & $3,54^{\mathrm{c}}$ & 0,34 & 0,0004 \\
\hline Pseudocolmo, $\mathrm{cm}$ & $48,83^{\mathrm{a}}$ & $36,31^{\mathrm{b}}$ & $32,07^{\mathrm{b}}$ & 2,74 & 0,007 \\
\hline Altura dossel, $\mathrm{cm}$ & $77,60^{\mathrm{a}}$ & $52,51^{\mathrm{b}}$ & $44,07^{\mathrm{b}}$ & 2,66 & 0,0002 \\
\hline
\end{tabular}

$\mathrm{EP}=$ erro-padrão da média; $\mathrm{P}=$ valor de probabilidade.

*Letras minúsculas na linha diferem a nível de 5\% de significância, pelo teste t. 
O número de folhas vivas por perfilho apresentou correlação positiva ( $\mathrm{R}=0,894$; $\mathrm{P}=0,0001)$ com a altura de dossel, resultado que vai de encontro ao que afirmam Garcez Neto et al. (2002), os quais obtiveram resposta linear positiva no número de folhas verdes de Panicum maximum cv. Marandu conforme aumentou a altura de corte, o que pode estar relacionado com a frequência de desfolha a que os perfilhos foram submetidos. Segundo Carvalho et al. (2001), dosséis mais altos tendem a ser submetidos às menores frequências e intensidades de desfolhação, enquanto os locais mais baixos do mesmo pasto, em geral, são pastejados de forma mais intensa e frequente pelos bovinos.

O diâmetro do colmo não foi influenciado significativamente pelos arranjos populacionais. Taiz e Zeiger (2004) observaram que, quanto maior a densidade populacional, menor o diâmetro do colmo. Esse fato ocorre porque, em altas populações, as plantas alocam seus recursos para um crescimento mais rápido, a fim de evitar o sombreamento, aumentando a possibilidade de crescimento acima do dossel, porém diminuindo o diâmetro de colmo, o que pode não ter sido significativamente diferente no presente estudo em razão do pastejo dos animais e da oferta de forragem utilizada.

O comprimento do pseudocolmo $(\mathrm{P}=0,949)$ e as alturas de dossel $(\mathrm{P}=0,521)$ não foram influenciados pelos arranjos populacionais, porém foram distintos significativamente ao longo dos períodos de avaliação, quando se observou uma redução no comprimento do pseudocolmo com o decorrer do ciclo da planta. Esse comportamento de diminuição da altura de pseudocolmo não é esperado com o avanço do ciclo fenológico da espécie, devido ao fato de que a planta tenderia ao alongamento dos entrenós na fase reprodutiva, como reportado por Confortin et al. (2010) em azevém anual (Lolium multiflorum). Tal resultado pode ser fruto da metodologia adotada, em que, em cada período de avaliação, novos perfilhos foram marcados, e, quando a planta avança, o ciclo de crescimento dos novos perfilhos tendem a ser de menor tamanho em razão de uma nova rota preferencial de fotoassimilados em detrimento dos novos perfilhos.

O mesmo comportamento é visualizado na Tab. 7 , onde a variável altura de dossel apresentou interação significativa entre densidade de plantio e período. A maior altura de dossel foi obtida no primeiro período em ambas as densidades; já no segundo período, a densidade de $12 \mathrm{~kg}$ apresentou altura de dossel intermediária, $59,87 \mathrm{~cm}$. A densidade de $24 \mathrm{~kg}$ apresentou a menor altura de dossel no segundo período, $45,15 \mathrm{~cm}$, sendo igual à obtida para as duas densidades no terceiro período de avaliação, 44,73 e $43,40 \mathrm{~cm}$ para as densidades de 12 e $24 \mathrm{~kg}$ de sementes. A maior altura de dossel visualizada para a densidade de $12 \mathrm{~kg}$ no segundo período em relação à densidade de $24 \mathrm{~kg}$, possivelmente, foi devido à oferta de forragem de 4,57\% de lâminas foliares que ocorreu no arranjo populacional de $22 \mathrm{~cm}$ de espaçamento entrelinha e $12 \mathrm{~kg}$ de sementes $\mathrm{ha}^{-1}$.

Tabela 7. Altura de dossel $(\mathrm{cm})$ da pastagem de sorgo forrageiro por período de avaliação de acordo com a densidade de sementes

\begin{tabular}{|c|c|c|c|c|c|c|}
\hline & & \multicolumn{3}{|c|}{ Período } & \multirow{2}{*}{ EP } & \multirow{2}{*}{$\mathrm{P}$} \\
\hline & & $21 / 12-04 / 01$ & $11 / 01-01 / 02$ & $15 / 02-11 / 03$ & & \\
\hline Densidade & $\begin{array}{l}12 \\
24\end{array}$ & $\begin{array}{l}72,23^{\mathrm{a}} \\
8296^{\mathrm{a}}\end{array}$ & $\begin{array}{l}59,87^{\mathrm{b}} \\
4515^{\mathrm{c}}\end{array}$ & $\begin{array}{l}44,73^{\mathrm{c}} \\
4340^{\mathrm{c}}\end{array}$ & 3,57 & 0,045 \\
\hline
\end{tabular}

Densidade $\left(\mathrm{kg} \mathrm{ha}^{-1}\right)$; $\mathrm{EP}=$ erro-padrão da média; $\mathrm{P}=$ valor de probabilidade da interação entre densidade $\mathrm{x}$ período; Letras minúsculas diferem a nível de 5\% de significância, pelo teste t.

O comprimento do pseudocolmo e o da altura de dossel apresentaram correlação positiva ( $\mathrm{R}=0,907 ; \mathrm{P}=0,0001)$, como também relatado por Pontes et al. (2003), que verificaram aumento de $0,58 \mathrm{~cm}$ na altura do pseudocolmo para cada $\mathrm{cm}$ a mais na altura do dossel de azevém anual.

\section{CONCLUSÕES}

Diferentes combinações de espaçamento entrelinha de plantio e densidade de sementes de sorgo forrageiro não alteram as características morfogênicas e estruturais de sorgo forrageiro. $\mathrm{O}$ estágio de crescimento da planta influencia nas características estruturais de sorgo forrageiro 
quando manejado sob pastoreio contínuo. Com o avançar do ciclo fenológico da planta, há um marcado decréscimo no crescimento e acúmulo de biomassa da pastagem de sorgo forrageiro.

\section{REFERÊNCIAS}

ALVARES, C.A.; STAPE, J.L.; SENTELHAS, P.C. et al. Köppen's climate classification map for Brazil. Meteorol. Z., v.22, p.711-728, 2013.

BANCO de dados meteorológicos para ensino e pesquisa. [Distrito Federal]: INMET, 2014. Disponível em: <http://www.inmet.gov.br/portal/index.php?r=bd mep/bdmep>. Acesso em: 10 maio 2015.

CARNEIRO, J.C.; NOVAES, L.P.; RODRIGUES, J.A.S. et al. Avaliação agronômica de híbridos de sorgo (Sorghum bicolor x Sorghum sudanense) sob regime de corte. In: CONGRESSO NACIONAL DE MILHO E SORGO, SIMPÓSIO BRASILEIRO SOBRE A LAGARTA-DO-CARTUCHO, SPODOPTERA FRUGIPERDA, 1, 25., 2004, Cuiabá. Anais... Cuiabá: CNMS, Embrapa Milho e Sorgo, 2004. CD-ROOM.

CARRÈRE, P.; LOUAULT, F.; SOUSSANA, J.F. Tissue turnover within grass-clover mixed swards grazed by sheep. Methodology for calculating growth, senescence and intake fluxes. J. Appl. Ecol., v.34, p.333-348, 1997.

CARVALHO, P.D.F.; RIBEIRO FILHO, H.M.N.; POLI, C.H.E.C. et al. Importância da estrutura da pastagem na ingestão e seleção de dietas pelo animal em pastejo. In: REUNIÃO ANUAL DA SOCIEDADE BRASILEIRA DE ZOOTECNIA, 38., 2001, Piracicaba. Anais...Piracicaba: [SBZ], 2001. v.1, p.853-871.

CHIELLE, Z.G.; TOMAZZI, D.J.; LOSSO, A.C. et al. Ensaio Sul-Rio-Grandense de sorgo para corte ou pastejo 2000/2001, resultados da rede estadual. In: REUNIÃO TÉCNICA ANUAL DO MILHO, REUNIÃO TÉCNICA ANUAL DO SORGO, 29., 46., 2001, Porto Alegre. Anais... Porto Alegre: EMATER/RS, 2001. CD-ROOM.

COELHO, A.M.; WAQUIL, J.M.; KARAM, D. et al. Seja o doutor do seu sorgo. Piracicaba: Arquivo do Agrônomo, 2002. Disponível em: <http://www.cnpms.embrapa.br/sorgo/doutorsor go.pdf>. Acessado em: 10 out. 2015.
CONFORTIN, A.C.C.; QUADROS, F.L.F.; ROCHA, M.G. et al. Morfogênese e estrutura de azevém anual submetido a três intensidades de pastejo. Acta Sci. Anim. Sci., v.32, p.385-391, 2010.

FAGUNDES, J.L.; FONSECA, D.M.; MISTURA, C. et al. Características morfogênicas e estruturais do capim-braquiária em pastagem adubada com nitrogênio avaliadas nas quatro estações do ano. Rev. Bras. Zootec., v.35, p.21-29, 2006.

GARCEZ NETO, A.F.; NASCIMENTO JUNIOR, D.; REGAZZI, A.J. et al. Respostas morfogênicas e estruturais de Panicum maximum cv. mombaça sob diferentes níveis de adubação nitrogenada e alturas de corte. Rev. Bras. Zootec., v.31, p.1890-1900, 2002.

GONTIJO NETO, M.M.; ALVARENGA, R.C.; PEREIRA FILHO, I.A. et al. Recomendações de densidades de plantio e taxas de semeaduras de culturas anuais e forrageiras em plantio consorciado. Sete Lagoas: Embrapa Milho e Sorgo, 2006. Disponível em: <http://www.cnpms.embrapa.br/publicacoes/publ ica/2006/comunicado/Com_137.pdf $>$. Acessado em: 10 out. 2015.

HODGSON, J. Grazing management. New York: Science into Pratice, 1990. 203p.

LEMAIRE, G.; CHAPMAN, D. Tissue flows in grazed plants communities. In: HODGSON, J.; ILLIUS, A.W. (Eds.). The ecology and management of grazing systems. Wallingford: [Cab Abstracts], 1996. 36p.

LOPES, C.M.; PACIULLO, D.S.C.; ARAÚJO, S.A.C. et al. Plant morphology and herbage accumulation of signal grass with or without fertilization, under different light regimes. Ciênc. Rural, v.47, p.1-7, 2017.

MARTINS, A.D.; SOUSA, L.F.; NÓBREGA, E.B. et al. Relação do nível de sombreamento artificial e da adubação sobre o desenvolvimento da forrageira Urochloa brizantha cv. Marandu. Rev. Bras. Saúde Prod. Anim., v.15, p.994-1005, 2014.

MARTINS, C.E.N.; QUADROS, F.L.F.; BANDINELLI, D.G. et al. Variáveis morfogênicas de milheto (Pennisetum americanum) mantido em duas alturas de pastejo. Ciênc. Rural, v.35, p.174-180, 2005. 
MARTUSCELLO, J.A.; FONSECA, D.M.; NASCIMENTO, J.R. et al. Características morfogênicas e estruturais do capim-xaraés submetido a adubação nitrogenada e desfolhação. Rev. Bras. Zootec., v.34, p.1475-1482, 2005.

MOOT, G.O.; LUCAS, H.L. The design conduct and interpretation of grazing trials on cultivated and improved pastures. In: PROCEEDINGS OF THE INTERNATIONAL GRASSLAND CONGRESS, 1952, Pensylvania. Proceedings... Pensylvania: State College, 1952. p.1380-1395. (Resumo).

NEUMANN, M.; RESTLE, J.; ALVES FILHO, D.C. et al. Qualidade de forragem e desempenho animal em pastagem de sorgo (Sorghum bicolor, L.), fertilizada com dois tipos de adubo, sob pastejo contínuo. Rev. Bras. Agrociênc., v.11, p.221-226, 2005.

PEDROSO, C.E.S.; MONKS, P.L.; FERREIRA, O.G.L. et al. Características estruturais de milheto sob pastejo rotativo com diferentes períodos de descanso. Rev. Bras. Zootec., v.38, p.801-808, 2009.
PEREIRA, V.V.; FONSECA, D.M.; MARTUSCELLO, J.A. et al. Características morfogênicas e estruturais de capim-mombaça em três densidades de cultivo adubado com nitrogênio. Rev. Bras. Zootec., v.40, p.26812689, 2011.

POMPEU, R.C.F.F.; CÂNDIDO, M.J.D.; NEIVA, J.N.M. et al. Fluxo de biomassa em capim tanzânia sob lotação rotativa com quatro níveis de suplementação concentrada. Rev. Bras. Zootec., v.38, p.809-817, 2009.

PONTES, L.S.; NABINGER, C.; CARVALHO, P.C.F. et al. Variáveis morfogênicas e estruturais de azevém anual (Lolium multiflorum Lam.) manejado em diferentes alturas. Rev. Bras. Zootec., v.32, p.814-820, 2003.

RODRIGUES, R.; AMORIM, S.E.P.; MELLO, M.A.A. et al. Características morfogênicas e estruturais do capim-Xaraés submetido a intensidades de desfolhas. Rev. Bras. Saúde Prod. Anim., v.15, p.430-439, 2014.

STRECK, E.V.; KÄMPF, N.; DALMOLIN, R.S.D. et al. Solos do Rio Grande do Sul. Porto Alegre: Epagri, 2008. 124p.

TAIZ, L.; ZEIGER, E. Fisiologia vegetal. 3.ed. Porto Alegre: Artmed, 2004. 618p. 